\title{
Identifying behavioral determinants of handwashing with soap after defecation in an urban setting in Bangladesh: Findings from a Barrier Analysis.
}

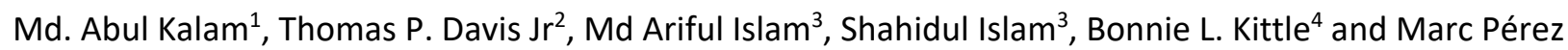
Casas $^{3}$.

1. Helen Keller International, Dhaka, Bangladesh.

2. World Vision International, Geneva, Switzerland.

3. SNV Netherlands Development Organization, Dhaka, Bangladesh.

4. Kittle Consultants, USA.

Correspondence:

Md. Abul Kalam.

Email: a.kalam724@gmail.com 


\section{Abstract}

Social and Behavioral Change (SBC) has long been considered as core component of hand washing with soap (HWWS) intervention, but identifying barriers and enablers of HWWS from a behavioral perspective is limited. By examining twelve potential behavioral determinants this Barrier Analysis study was conducted to identify the barriers and enablers of HWWS after defecation in urban setting in Bangladesh. We conducted 45 interviews with those who washed their hands with soap after defecation ("Doers") and another 45 interviews with those who did not ("Non-doers"). Data analysis was performed to identify which beliefs were most highly-associated with hand washing with soap. The analysis showed that two of the main barriers of HWWS after defecation were related to perceived self-efficacy and access, especially availability of soap. Non-doers claimed that access to soap was difficult due to lack of money and unavailability at nearby shops. Other important determinants such as difficulty remembering to buy soap (cues for action)), believing that most people did not approve of HWWS (e.g. perceived social norms), low perceived severity of diarrhea, and not believing that HWWS would work to reduce diarrhea (perceived action efficacy) were significantly correlated with adoption of the behavior. Perceived divine will (believing that it is God's will when one gets diarrhea) was also a factor among the Non-doers. Other benefits such as feeling clean and keeping free from illness were reported more often by Doers, while Non-doers were more likely to report increased costs as a barrier to HWWS. The results suggest that an integrated behavior change strategy promoting specific beliefs about HWWS using culturally-inclusive messaging and activities to address the different barriers and leverage the different enablers may lead to better adoption of HWWS.

Key words: Handwashing with Soap, Hygiene and Sanitation, Barrier Analysis, Behavioral Determinants, Behavior Change, Bangladesh. 


\section{Highlights}

- Examining specific behavioral determinants, this is the first study in urban Bangladesh which aimed at identifying barriers and facilitators of handwashing with soap.

- Behavioral determinants associated with the behavior included perceived self-efficacy, access, cues for action, perceived social norms, perceived severity, perceived divine will, positive consequences of the behavior, and perceived action efficacy, indicating that practitioners may need to do broad messaging to bring about behavior change.

- An effective behavior change strategy for HWWS after defecation will be required in this urban setting to address multiple beliefs and behavioral determinants, reducing barriers and leveraging enablers identified in this study. 


\section{Introduction}

Handwashing with soap (HWWS) at critical times (e.g., after defecation) is known to be an effective strategy to prevent diarrheal and infectious diseases. Evidence from randomized controlled trials suggests that HWWS may decrease diarrhea by $47 \%$ (1), pneumonia and other respiratory infections by $50 \%$ (2), and parasitic infections (3). The recent pandemic, caused by severe acute respiratory syndrome coronavirus 2 (SARS-CoV-2) also supports the importance of HWWS to prevent the risk of infection (4) Among other non-clinical measures, HWWS was found to be one of the most effective approaches in preventing SARS-CoV-2 infection (5). Public health interventions on HWWS have long been considered as one of the most cost-effective approaches to reduce the burden of disease (6). However, it has been estimated that only $19 \%$ of the global population wash their hands with soap after defecation or management of children's excreta (7) and Bangladesh is not an exception. Despite the increased risk of diarrheal disease morbidity and mortality among the Bangladeshi population, increasing handwashing has been a major challenge in the country (8).

Empirical evidence has identified a range of behavioral determinants effect on people's handwashing with soap practices. These determinants include the availability of handwashing facilities, access to soap and water, social and cultural norms and supportive environment, motivations, affiliation, knowledge on positive outcome and risk, skills, and broader social and structural factors (9). Access to a handwashing facility with soap is another important barrier to HWWS (10). Using a nationally-representative sample, the 2014 Bangladesh National Hygiene Survey showed that 70\% of urban households had a handwashing facility for use post-defecation with soap and water while poorer, urban households were less likely to have one (11). Nevertheless, other factors such as the desire to feel clean have also been identified as behavioral determinants of handwashing with soap. A systematic review on formative studies from 11 countries in Asia, Africa, and South America showed that emotional drivers (e.g., disgust, comfort, and the desire for social status) are often key determinants of handwashing behavior (12). Little information is 
available on which behavioral determinants are important to consider in promoting HWWS in the Bangladeshi context. Most previous studies in Bangladesh focused on identifying the gap between handwashing knowledge and practices and proxy indicators such as access to a hand washing facility (13), observing cleanliness of handwashing (14) and the association of household characteristics with handwashing with soap (15). Therefore, this study aimed at studying a broader array of behavioral determinants and their association with behavioral adoption to inform behavior change communication strategies and to better design contextualized activities to promote HWWS after defecation in Bangladesh. This study also contributes to the development of a comprehensive Social \& Behavioral Change (SBC) strategy and culturally inclusive program activities.

\section{Methodology}

\section{Study site and context}

This Barrier Analysis study was conducted in Gazipur City Corporation (GCC) which was formed in 2013, merging then Tongi and Gazipur Municipalities, along with large semi-urban and rural areas. In 2017, an initiative entitled "Development of Integrated Wastewater Management System for Gazipur City Corporation (GCC)" was started under the guidance of the Greater Dhaka Watershed Restoration (GDWR) Work-Stream of the Bangladesh Water Multi-Stakeholder Partnership (MSP), supported by the 2030 Water Resources Group (2030WRG) under the World Bank. SNV is providing advisory technical assistance to the city council as part of its WASH SDG Program. The aim of this program is to enhance the capacity of the city authority so it can provide citywide, safely-managed hygiene and sanitation. A baseline population-based study found that $54.7 \%$ of the households have a handwashing station within ten meters of the toilet with access to water but without access to soap. The majority of people who had a handwashing station with soap did not have a water source that prevented contamination of water by hands. In order to address this, the city authority agreed to implement an SBC intervention to influence 
household demand for - and adoption of - improved hygiene and sanitation services. As part of a larger formative research plan to design the SBC strategy, this Barrier Analysis study aimed to identify important beliefs and other important responses regarding the behavioral determinants of HWWS in this population in order to create contextualized messages and activities that better address the barriers and enablers of handwashing with soap after defecation.

\section{Study tool}

As part of Designing for Behavior Change approach the Barrier Analysis (BA) is a formative research tool that was developed in 1990 by Davis, based on an earlier Doer/Non-doer Analysis tool, and popularized by Kittle and Davis. BA has now been used in more than 75 countries by more than 30 INGOs and multilaterals (e.g., UNICEF), both alone and as part of the Designing for Behavior Change approach. Crosssectional surveys, key informant interviews (KIIs) and focus group discussions (FGDs) have often been used to explore different beliefs and possible drivers of HWWS and other behaviors. However, commonlyheld beliefs about a behavior and other characteristics of adopters are not necessarily linked with adoption of a behavior and can lead an implementer astray when planning what to change through an intervention. Barrier Analysis is meant to make up for that shortcoming by identifying beliefs and other responses associated with behavioral determinants that are correlated (at the $p<0.05$ level) with adoption of a behavior. BA draws mostly from the Health Belief Model and Theory of Reasoned Action model, and has been used mostly to study health, nutrition, and WASH behaviors (e.g., HWWS), but also behaviors from other sectors (e.g., agriculture, gender, education, and livelihoods). The beliefs and other responses regarding behavioral determinants (e.g., perceived self-efficacy, perceived social norms, perceived risk) assessed during BA are identified so that more effective behavior change communication messages, strategies and supporting activities can be developed, with a focus on the most actionable findings. More than 17 BA studies from 11 countries have been conducted on HWWS. A summary of those studies found that the most common determinants (across countries) of HWWS were perceived social norms, perceived 
self-efficacy, positive and negative consequences of the behavior, access, and perceived susceptibility (to diarrhea) (16) While many BA studies can be found in the gray literature on behaviors such as birth preparedness $(17,18)$ feeding fish to children $(19)$ and other agriculture and nutrition behaviors in Myanmar (20) consumption of iron-rich foods among adolescent girls in Nepal (21) infant and young child feeding and maternal nutrition behaviors in Syria (22) use of household water treatment technology (23) and various health, nutrition, and WASH behaviors in Liberia (24) There are also several BA studies in the peer-reviewed literature on exclusive breastfeeding (25) HWWS among internally displaced women in the Kurdistan region of Iraq (10) timely oral polio vaccination (26) agricultural extension behaviors (27) dietary salt reduction in Nepal (28) transition from the lactational amenorrhea method to other modern family planning methods in Bangladesh (29) and cervical cancer screening in Senegal (30)

\section{Questionnaire development}

This study adapted the standardized Barrier Analysis questionnaire from the Designing for Behavior Change (DBC) training manual (31) for exploring key beliefs and other responses regarding the behavioral determinants of handwashing behavior. As recommended by the BA developers, the research design began with defining the behavior, the details of when and how the behavior needs to be practiced, and using information from the earlier baseline study - the priority groups for the behavior (see Box 1).

Box 1: Key definitions based on Barrier Analysis approach

\begin{tabular}{|l|l|}
\hline Key terms & Definition \\
\hline Study behavior & Handwashing with soap after defecation. \\
\hline Target group & Women and men \\
\hline Details of the behavior & Women and men wash their hands with soap every time after defecation. \\
\hline Behavioral determinants & \multicolumn{2}{|l|}{$\begin{array}{l}\text { An individual's belief that he/she can wash their hands with soap every } \\
\text { time after defecation given his/her current knowledge and skills }\end{array}$} \\
\hline Perceived self-efficacy &
\end{tabular}




\begin{tabular}{|c|c|}
\hline Perceived social norms & $\begin{array}{l}\text { The perception that people important to an individual think that he/she } \\
\text { should wash their hands with soap every time after defecation. }\end{array}$ \\
\hline $\begin{array}{l}\text { Perceive positive } \\
\text { consequences }\end{array}$ & $\begin{array}{l}\text { The positive things a person thinks will happen as a result of handwashing } \\
\text { with soap every time after defecation. }\end{array}$ \\
\hline $\begin{array}{l}\text { Perceived negative } \\
\text { consequences }\end{array}$ & $\begin{array}{l}\text { The negative things a person thinks will happen as a result of handwashing } \\
\text { with soap every time after defecation. }\end{array}$ \\
\hline Access & $\begin{array}{l}\text { The availability of the needed products or services (e.g., soap, water, } \\
\text { handwashing facilities) required for handwashing with soap every time } \\
\text { after defecation. This includes real and perceived barriers related to the } \\
\text { cost, distance, and cultural acceptability of these products and services }\end{array}$ \\
\hline $\begin{array}{l}\text { Cues to action / } \\
\text { reminders }\end{array}$ & $\begin{array}{l}\text { The presence of reminders that help a person remember to wash their } \\
\text { hands with soap every time after defecation. }\end{array}$ \\
\hline Perceived susceptibility & A person's perception of how vulnerable or at risk they are to get diarrhea. \\
\hline Perceived severity & $\begin{array}{l}\text { The extent to which a person believes that getting diarrhea would be very } \\
\text { serious. }\end{array}$ \\
\hline Perceived action efficacy & $\begin{array}{l}\text { The extent to which a person believes that by practicing handwashing with } \\
\text { soap every time after defecation they will be able to avoid getting diarrhea. }\end{array}$ \\
\hline Perceived divine will & $\begin{array}{l}\text { The extent to which a person believes that it is Allah's will (or the gods' } \\
\text { will) for him/her to get diarrhea }\end{array}$ \\
\hline Policy & $\begin{array}{l}\text { The presence of laws and regulations that may affect whether people wash } \\
\text { their hands with soap every time after defecation. }\end{array}$ \\
\hline Culture & $\begin{array}{l}\text { The extent to which cultural rules or taboos that may affect whether } \\
\text { people wash their hands with soap every time after defecation. }\end{array}$ \\
\hline
\end{tabular}

The BA questionnaire is divided into two parts. The first part includes a set of screening questions to identify the participant as either a 'Doer' (a person who claims to wash their hands after the last time they defecated using soap and water, and has soap that has been used at a hand washing station) or a 'Nondoer' (a person who does not regularly practice handwashing with soap after defecation, or does not have soap [used or unused] at the handwashing station). In the screening section of the questionnaire, both self-reported handwashing behavior and the observed presence of used soap at the handwashing facility were used. The second part of the questionnaire consists of open- and closed-ended questions relating to each of the twelve determinants assessed with Barrier Analysis (described in the Box 1). While not part 
of the traditional BA approach, along with the determinant on access, structured observations were done to record the presence of a handwashing facility within 10 feet of a latrine or toilet, presence of a permanent handwashing facility in the home, and presence of covered bucket of water used only for handwashing purposes. The questionnaire was developed in English and then was translated into Bengali and back-translated into English to check for accuracy.

\section{Sampling}

Adult men and women were the Priority Group for this BA study, and were selected through random sampling from both slum and non-slum areas. The Barrier Analysis approach recommends a sample size of 45 doers and 45 non-doers in order to detect statistically-significant Odds Ratios of 3.0 or higher at a confidence level of $90 \%$ (32) For this study behavior, 23 doers and 22 non-doers were selected from slum areas and another 22 doers and 23 non-doers were selected from non-slum areas in order to make the results more applicable to both contexts.

\section{Data collection, management and analysis}

Data was collected through individual interviews with responses recorded on paper questionnaires by two teams with one female and one male in each team. The data collection team and the lead author coded the open-ended responses thematically, using both an inductive and deductive coding process. At the end of this process, the team quantified the responses in each category for Doers and Non-doers separately. These categories and the number of responses registered for each were then entered into a standardized BA tabulation sheet that revealed which response were significant and should be addressed by the behavior change strategy. For each question and category of responses, the BA tabulation calculates the percentage of responses for both Doers and Non-doers; the Odds Ratio, the Standard Error, and its confidence interval; the Estimated Relative Risk; and p-values. This allows the user to identify those 
differences between Doers and Non-doers that are statistically significant $($ at $p<0.05)$ and to see the strength of those associations between each response and the behavior (based on the ERR).

\section{Ethical considerations}

Since this was a brief formative study that is routinely used in business-as-usual development projects without collection of personally-identified data, an IRB was not sought. The study was approved by the senior management of GCC in consultation with higher leadership. Data collectors were informed of the study objectives prior to taking part in the interviews, and all respondents were asked to give their written consent before they were interviewed. As part of the informed consent process, the purpose of the study and all survey procedures were explained. All respondents had the right to withdraw from the interview at any moment without jeopardizing their access to any services. No identifying data such as name, date of birth or address was collected from the respondents.

\section{Results}

The results are presented based on the highest, statistically-significant differences in responses and beliefs between Doers and Non-doers of HWWS after defecation. The detailed results are included in Supplementary file 2 . These beliefs and determinants are discussed below.

\section{(1) Self-efficacy and (2) Access}

When responding to the open-ended question on what makes (or would make) the behavior easier (see Table 1), respondents mentioned access issues. Doers were 22.9 times more likely to mention availability of soap $(p=0.000)(p<0.000)$ than Doers. Non-doers were 26 times more likely to mention lower price of soap $(\mathrm{p}<0.000)$. When responding to the open-ended question on what makes (or would make) the behavior difficult, Non-doers were 7.1 times more likely to mention (than Doers) an inability to buy soap $(p=0.008)$, an access issue). Doers were 25.2 times more likely to mention availability of water as something that makes the behavior easier. However, when asked directly (using a closed-ended question) 
how difficult it was to get water for HW, the responses of Doers and Non-doers were not statistically different (with $11 \%$ of Doers and $7 \%$ of Non-doers saying it was difficult or very difficult). Also, based on household observations, Doers were found to be 2.9 times more likely to have a permanent HW facility in the home $(p<0.000)$ and 2.1 times more likely to have a HW facility within 10 feet of a latrine or toilet $(p=0.01)$ than Doers, and Non-doers were 2.4 times more likely to not have a covered bucket for HW purposes $(p=0.01)$ than Doers.

Table 1: Perceived Self-efficacy and Access

\begin{tabular}{|l|l|l|l|l|l|l|l|}
\hline Determinant/responses & \multicolumn{4}{|l|}{$\begin{array}{l}\text { Total Doers }=45 \\
\text { Total Non-doers }=45\end{array}$} \\
\cline { 2 - 7 } & $\begin{array}{l}\text { Doers } \\
\mathrm{n}(\%)\end{array}$ & $\begin{array}{l}\text { Non-doers } \\
\mathrm{n}(\%)\end{array}$ & Diff. & Odds Ratio & $\begin{array}{l}\text { Confidence } \\
\text { Interval }\end{array}$ & ERR* & $\begin{array}{l}\mathrm{p} \text { - } \\
\text { value }\end{array}$ \\
\hline
\end{tabular}

Self-efficacy: What makes you easier to wash your hands with soap after defecation?

\begin{tabular}{|l|l|l|l|l|l|l|l|}
\hline Availability of soap & $44(98 \%)$ & $22(49 \%)$ & $49 \%$ & 46.00 & $5.82-22.91$ & 22.91 & 0.000 \\
\hline Availability of water & $43(96 \%)$ & $9(20 \%)$ & $76 \%$ & 86.00 & $17.45-423.79$ & 25.16 & 0.000 \\
\hline Low price of soap & $1(2 \%)$ & $25(56 \%)$ & $-53 \%$ & 0.02 & $0.00-0.14$ & 0.04 & 0.000 \\
\hline
\end{tabular}

Self-efficacy: What makes you difficult to wash your hands with soap after defecation?

\begin{tabular}{|l|l|l|l|l|l|l|l|}
\hline $\begin{array}{l}\text { When I am outside of } \\
\text { home }\end{array}$ & $29(64 \%)$ & $3(7 \%)$ & $58 \%$ & 25.38 & $6.77-95.07$ & 5.00 & 0.000 \\
\hline Inability to buy soap & $1(2 \%)$ & $9(20 \%)$ & $-18 \%$ & 0.09 & $0.01-075$ & 0.14 & 0.008 \\
\hline Difficult to remember & $4(9 \%)$ & $15(33 \%)$ & $-24 \%$ & 0.20 & $0.06-0.65$ & 0.29 & 0.004 \\
\hline
\end{tabular}

*ERR = Estimated Relative Risk

When asked specifically about access (see Table 2), Non-doers were 8.9 times more likely to say that it was "very difficult" to get soap to wash hands ( $p=0.002)$, and 5.1 times more likely to say it was "somewhat difficult" $(p<0.000)$. Conversely, Doers were 9.7 times more likely to say that it was "not difficult" to get soap $(p<0.000)$. When asked what makes it difficult to get soap, Non-doers were 18.7 times more likely to mention a financial crisis in their family $(p=0.000)$, and 15.1 times more likely to mention unavailability of soap at nearby markets $(p<0.000)$ than Non-doers.

Table 2: Perceived Access, reasons behind difficulty in access to water and soap and proxy measures 


\begin{tabular}{|c|c|c|c|c|c|c|c|}
\hline \multirow[t]{2}{*}{ Determinant/responses } & \multicolumn{7}{|c|}{$\begin{array}{l}\text { Total Doers }=45 \\
\text { Total Non-doers }=45\end{array}$} \\
\hline & $\begin{array}{l}\text { Doers } \\
\mathrm{n}(\%)\end{array}$ & $\begin{array}{l}\text { Non-doers } \\
n(\%)\end{array}$ & Diff. & Odds Ratio & $\begin{array}{l}\text { Confidence } \\
\text { Interval }\end{array}$ & $\mathrm{ERR}^{*}$ & $\begin{array}{l}\mathrm{p}- \\
\text { value }\end{array}$ \\
\hline \multicolumn{8}{|c|}{ Access: How difficult it is to get soap to wash your hands with soap after defecation? } \\
\hline Very Difficult & 1 & $11(24 \%)$ & $-22 \%$ & 0.07 & $0.01-0.57$ & 0.11 & 0.002 \\
\hline Somewhat Difficult & $5(11 \%)$ & $24(53 \%)$ & $-42 \%$ & 0.11 & $0.04-0.33$ & 0.20 & 0.000 \\
\hline Not Difficult & $40(89 \%)$ & $10(22 \%)$ & $67 \%$ & 28.00 & $8.73-89.81$ & 9.69 & 0.000 \\
\hline \multicolumn{8}{|c|}{ Access: What makes it difficult to get soap to wash your hands with soap after defecation? } \\
\hline $\begin{array}{l}\text { Financial crisis in family } \\
\text { (chronic poverty) }\end{array}$ & $1(2 \%)$ & $20(44 \%)$ & $-42 \%$ & 0.03 & $0.00-0.22$ & 0.05 & 0.000 \\
\hline $\begin{array}{l}\text { Unavailability of soap at } \\
\text { nearby stores }\end{array}$ & $1(2 \%)$ & $17(38 \%)$ & $-36 \%$ & 0.04 & $0.00-0.30$ & 0.07 & 0.000 \\
\hline \multicolumn{8}{|c|}{ Hand Washing facility within 10 feet? } \\
\hline Yes & $19(42 \%)$ & $8(18 \%)$ & $24 \%$ & 3.38 & $1.29-8.88$ & 2.06 & 0.010 \\
\hline No & $26(58 \%)$ & $37(82 \%)$ & $-24 \%$ & 0.30 & $0.11-0.78$ & 0.49 & 0.010 \\
\hline \multicolumn{8}{|c|}{ Presence of hand washing permanent facility } \\
\hline Yes & $21(47 \%)$ & $5(11 \%)$ & $36 \%$ & 7.00 & $2.33-21.00$ & 2.87 & 0.000 \\
\hline No & $24(53 \%)$ & $40(89 \%)$ & $-36 \%$ & 0.14 & $0.05-0.43$ & 0.35 & 0.000 \\
\hline \multicolumn{8}{|c|}{ Presence of covered bucket to preserve water for hand washing purpose } \\
\hline Yes, but without cover. & $26(58 \%)$ & $35(78 \%)$ & $-20 \%$ & 0.39 & $0.16-0.98$ & 0.56 & 0.035 \\
\hline No bucket & $10(22 \%)$ & $2(4 \%)$ & $18 \%$ & 6.14 & 1.26 & 2.41 & 0.013 \\
\hline
\end{tabular}

\section{${ }^{*} E R R=$ Estimated Relative Risk}

\section{(3) Cues for action}

When responding to the closed-ended question on whether it was easy to remember to do the behavior

(see Table 3), Doers were 8.5 times more likely to say that it was "not difficult" to remember $(p<0.000)$

than Non-doers. Non-Doers were 15.2 times more likely to say that it was "very difficult" $(p<0.000)$ and 3.4 times more likely to say that it was "somewhat difficult" to remember $(p<0.000)$ than Doers. 
Table 3: Cues for action and Social norms

\begin{tabular}{|c|c|c|c|c|c|c|c|}
\hline \multirow[t]{2}{*}{ Determinant/responses } & \multicolumn{7}{|c|}{$\begin{array}{l}\text { Total Doers }=45 \\
\text { Total Non-doers }=45\end{array}$} \\
\hline & $\begin{array}{l}\text { Doers } \\
\mathrm{n}(\%)\end{array}$ & $\begin{array}{l}\text { Non-doers } \\
\mathrm{n}(\%)\end{array}$ & Diff. & Odds Ratio & $\begin{array}{l}\text { Confidence } \\
\text { Interval }\end{array}$ & $\mathrm{ERR}^{*}$ & $\begin{array}{l}p- \\
\text { value }\end{array}$ \\
\hline \multicolumn{8}{|c|}{ Cues for action: How difficult to remember to wash your hands with soap after defecation? } \\
\hline Very Difficult & $1(2 \%)$ & $17(38 \%)$ & $-36 \%$ & 0.04 & $0.00-0.30$ & 0.07 & 0.000 \\
\hline Somewhat Difficult & $8(18 \%)$ & $25(56 \%)$ & $-38 \%$ & 0.17 & $0.07-0.45$ & 0.29 & 0.000 \\
\hline Not Difficult & $\begin{array}{l}36 \\
(80 \%)\end{array}$ & $3(7 \%)$ & $73 \%$ & 64.75 & 14.08-222.69 & 8.51 & 0.000 \\
\hline \multicolumn{8}{|c|}{ Social norms: Do most of the people you know approve you to wash your hands with soap after defecation? } \\
\hline Yes & $\begin{array}{l}44 \\
(100 \%)\end{array}$ & $30(67 \%)$ & $31 \%$ & 22.0 & $2.76-175.53$ & 12.85 & 0.000 \\
\hline Possibly & $1(2 \%)$ & $12(27 \%)$ & $-24 \%$ & 0.06 & $0.01-0.50$ & 0.10 & 0.001 \\
\hline \multicolumn{8}{|c|}{ Social norms: Who are the people that approve you to wash your hands with soap after defecation? } \\
\hline $\begin{array}{l}\text { HH members (Husband, } \\
\text { wife, mother, son, daughter, } \\
\text { father) }\end{array}$ & $\begin{array}{l}43 \\
(96 \%)\end{array}$ & $28(62 \%)$ & $33 \%$ & 13.05 & $2.80-60.92$ & 7.66 & 0.000 \\
\hline Teachers & $\begin{array}{l}34 \\
(76 \%)\end{array}$ & $16(36 \%)$ & $40 \%$ & 5.60 & $2.25-13.97$ & 3.17 & 0.000 \\
\hline NGO agents & $\begin{array}{l}27 \\
(60 \%) \\
\end{array}$ & $5(11 \%)$ & $49 \%$ & 12.00 & $3.98-36.21$ & 3.86 & 0.000 \\
\hline Doctors & $\begin{array}{l}21 \\
(47 \%)\end{array}$ & $12(27 \%)$ & $20 \%$ & 2.41 & $1.00-5.82$ & 1.73 & 0.040 \\
\hline
\end{tabular}

${ }^{*} E R R=$ Estimated Relative Risk

\section{(4) Perceived social norms}

When asked if most people the respondent knew approved (or would approve) of their washing their hands with soap after defecation (see Table 3), Doers were 12.9 times more likely to say yes $(p<0.000)$ than Non-doers. When asked who the people are (or would be) that approve (or would approve), Doers were 7.7 times more likely to say household members $(p<0.000), 3.2$ times more likely to say teachers $(p<0.000), 3.9$ times more likely to say NGO agents $(p<0.000)$ and 1.7 times more likely to say doctors $(p=0.04)$. 


\section{(5) Perceived severity, (6) Perceived divine will}

When asking the respondents how serious it would be if he or she got diarrhea in the coming months (see

Table 4), Doers were found to be 2.7 times more likely to say that it would be "very serious" ( $p=0.001)$ and Non-doers were found to be 5.9 times more likely to say that it would be "not serious" $(p<0.000)$. When asked if the respondent believed it was Allah's will that people get diarrhea, Non-doers were 3.7 times more likely to believe that it is Allah's will ( $p=0.002)$, and Doers were 1.8 times more likely to say that it was not $(p=0.03)$.

Table 4: Perceived severity, perceived divine will and perceived risk

\begin{tabular}{|c|c|c|c|c|c|c|c|}
\hline \multirow[t]{2}{*}{ Determinant/responses } & \multicolumn{7}{|c|}{$\begin{array}{l}\text { Total Doers }=45 \\
\text { Total Non-doers }=45\end{array}$} \\
\hline & $\begin{array}{l}\text { Doers } \\
\mathrm{n}(\%)\end{array}$ & $\begin{array}{l}\text { Non-doers } \\
n(\%)\end{array}$ & Diff. & Odds Ratio & $\begin{array}{l}\text { Confidence } \\
\text { Interval }\end{array}$ & ERR* & $\begin{array}{l}p \text { - } \\
\text { value }\end{array}$ \\
\hline \multicolumn{8}{|c|}{ Perceived severity: How serious it would be if you get diarrhea in coming months? } \\
\hline Very serious & $18(40 \%)$ & $4(9 \%)$ & $31 \%$ & 6.83 & $2.08-22.40$ & 2.73 & 0.001 \\
\hline Not Serious & $4(9 \%)$ & $23(51 \%)$ & $-42 \%$ & 0.09 & $0.03-0.30$ & 0.17 & 0.000 \\
\hline \multicolumn{8}{|c|}{ Divine will: Do you think that God is responsible to get diarrhea? } \\
\hline Yes & $4(9 \%)$ & $16(36 \%)$ & $-27 \%$ & 0.18 & $0.05-0.58$ & 0.27 & 0.002 \\
\hline No & $30(67 \%)$ & $20(44 \%)$ & $22 \%$ & 2.50 & $1.06-5.87$ & 1.84 & 0.028 \\
\hline \multicolumn{8}{|c|}{ Perceived risk: How likely to get diarrhea in coming months? } \\
\hline Somewhat Likely & $25(56 \%)$ & $38(84 \%)$ & $-28 \%$ & 0.23 & $0.08-0.62$ & 0.43 & 0.003 \\
\hline Not Likely & $13(29 \%)$ & $1(2 \%)$ & $28 \%$ & 17.88 & $2.22-143-70$ & 3.15 & 0.000 \\
\hline
\end{tabular}

${ }^{*} E R R=$ Estimated Relative Risk

(7) Perceived positive and negative consequences of the behavior

Overall, in response to an open-ended question about the advantages of performing this behavior (see

Table 5), Doers were 3.3 times more likely to say "feeling clean" ( $p=0.045)$ and 2.6 times more likely to say being "free from illness" were advantages of the behavior. When asked about the disadvantages of 
performing this behavior, Non-Doers were 2.8 times more likely to mention "increasing costs" as a disadvantage of the behavior.

Table 5: Perceived positive and negative consequences of the behavior

\begin{tabular}{|l|l|l|l|l|l|l|l|}
\hline Determinant/responses & \multicolumn{2}{|l|}{$\begin{array}{l}\text { Total Doers } 45 \\
\text { Total Non-doers }=45\end{array}$} \\
\cline { 2 - 7 } & $\begin{array}{l}\text { Doers } \\
\mathrm{n}(\%)\end{array}$ & $\begin{array}{l}\text { Non-doers } \\
\mathrm{n}(\%)\end{array}$ & Diff. & Odds Ratio & $\begin{array}{l}\text { Confidence } \\
\text { Interval }\end{array}$ & ERR* & $\begin{array}{l}\mathrm{p} \text { - } \\
\text { value }\end{array}$ \\
\hline
\end{tabular}

Positive consequences: What are the positive consequences of washing hands with soap after defecation?

\begin{tabular}{|l|l|l|l|l|l|l|l|}
\hline Feeling clean & $43(96 \%)$ & $37(82 \%)$ & $13 \%$ & 4.65 & $0.93-23.27$ & 3.26 & 0.045 \\
\hline Free from illness & $12(27 \%)$ & $2(4 \%)$ & $22 \%$ & 7.82 & $1.64-37.36$ & 2.64 & 0.004 \\
\hline
\end{tabular}

Negative consequences: What are the negative consequences of washing hands with soap after defecation?

\begin{tabular}{|l|l|l|l|l|l|l|l|}
\hline Increasing cost & $3(7 \%)$ & $10(22 \%)$ & $-16 \%$ & 0.25 & $0.06-.98$ & 0.35 & 0.034 \\
\hline Don't know & $27(76 \%)$ & $25(40 \%)$ & $36 \%$ & 4.64 & $0.52-2.77$ & 1.13 & 0.001 \\
\hline
\end{tabular}

*ERR = Estimated Relative Risk

\section{(8) Perceived Action Efficacy}

Doers and Non-doers were equally likely to say that it was "very likely" that they would get diarrhea if they washed their hands with soap every time after defecation. However, Non-doers were 2.5 times more likely to say that it was "not likely" that they would get diarrhea $(p=0.004)$ if they did not wash hands, and Doers were 2.3 times more likely to say that was "somewhat likely" ( $p=0.005)$.

Table 6: Perceived action efficacy, culture and policy.

\begin{tabular}{|c|c|c|c|c|c|c|c|}
\hline \multirow[t]{2}{*}{ Determinant/responses } & \multicolumn{7}{|c|}{$\begin{array}{l}\text { Total Doers }=45 \\
\text { Total Non-doers }=45\end{array}$} \\
\hline & $\begin{array}{l}\text { Doers } \\
\mathrm{n}(\%)\end{array}$ & $\begin{array}{l}\text { Non-doers } \\
\mathrm{n}(\%)\end{array}$ & Diff. & Odds Ratio & $\begin{array}{l}\text { Confidence } \\
\text { Interval }\end{array}$ & ERR* & $\begin{array}{l}p- \\
\text { value }\end{array}$ \\
\hline \multicolumn{8}{|c|}{ Action Efficacy: How likely are you to get diarrhea if you wash your hand with soap after defecation? } \\
\hline Somewhat Likely & $32(71 \%)$ & $19(42 \%)$ & $29 \%$ & 3.37 & $1.40-8.08$ & 2.25 & 0.005 \\
\hline Not Likely & $9(20 \%)$ & $22(49 \%)$ & $-29 \%$ & 0.26 & $0.10-0.67$ & 0.39 & 0.004 \\
\hline \multicolumn{8}{|c|}{$\begin{array}{l}\text { Policy - Are there any community/national laws or rules in place that make it more likely to perform the } \\
\text { behavior? }\end{array}$} \\
\hline No & $40(89 \%)$ & $31(69 \%)$ & $20 \%$ & 3.61 & $1.17-11.11$ & 2.56 & 0.018 \\
\hline
\end{tabular}

*ERR = Estimated Relative Risk 


\section{Discussion}

This Barrier Analysis study on handwashing with soap after defecation revealed important differences in responses and beliefs between Doers and Non-doers regarding eight different (but sometimes linked) behavioral determinants of HWWS in this urban setting of Bangladesh. This finding alone helps one to better understand why hand washing with soap has been a difficult behavior to scale in many countries. Even if one or two determinants or barriers are addressed, there are a multitude of important determinants and barriers that may make it difficult for a person to adopt the behavior, and many deserve attention. Indeed, in a study of 16 different BA studies on HWWS in ten different countries, perceived self-efficacy and access were significant determinants in $69 \%$ and $50 \%$ of those studies (respectively). However, access was not the only issue: Other determinants found to be important in our study were important in the majority of those studies, as well, such as perceived social norms ( $75 \%$ of the studies) and positive/negative consequences of the behavior (56\%) (16)

The largest drivers of this behavior in this population - based on responses to questions on the 12 determinants studied - were around beliefs and responses regarding self-efficacy and access. Randomized controlled trials and population-based research has shown that integrating handwashing facility into WASH programs may increase HWWS (33) and access to soap and water is a vital component in assuring HWWS in many contexts $(34,35)$. This study confirmed those findings. Doers (those who washed their hands with soap every time after defecation) were much more likely to say that they could do the behavior with their current knowledge, skills and resources than Non-doers. Key enablers included availability of soap (especially low-priced soap) and money (presumably for purchasing soap), and key barriers included unavailability of soap in local markets and difficulty in remembering to buy soap for hand washing. When asked the open-ended question, "what makes it easier?" Doers were more likely to mention that having water made it easier (than Non-doers), but when asked specifically "how difficult is 
it to get water that you need to wash your hands every time after defecation?," there were no significant differences between Doers and Non-doers. Non-doers were more likely to say that getting soap was very difficult when asked the similar closed-ended question, so soap availability appears to be a more important barrier than water access in this population. Findings from the observation on handwashing facilities show that having a permanent HW facility in the home that is less than 10 feet from a latrine or toilet, and having a covered bucket of water for HW purposes are important, as well. In this urban context, poorer people are living in the slum setting where access to a handwashing station with soap has been found to be a major barrier in this and other studies (34). Also, it is widely accepted that access to a handwashing facility is an important determinant of HWWS in lower income settings globally (10) and having a handwashing facility is a critical determinant of HWWS in critical times including after defecation (36). These findings confirm that relationship in our study.

Cues for action - specifically, being able to remember to do the behavior - is another important behavioral determinant of HWWS in this population. Results of our study showed that Non-doers were more likely to say that it is very difficult to remember to perform the behavior and represents a barrier for them. This result is aligned with other previous studies of Bangladesh in domestic, community and school-based WASH interventions (8,37).

Perceived social norms were found to be a powerful determinant of HWWS in this study. In addition to Doers being much more likely to say that "most people approve," they were more likely to mention key groups who they believe approve: household members, NGO agents, teachers, and doctors. These groups should be reached with messaging and used as key influencers of the behavior in this context. Other studies have found that perceived social norms and self-efficacy can be powerful factors in adoption of WASH behaviors (8) and determinants associated with the HBM are often found to be driving adoption of HW behavior (38). Perceived severity of diarrhea was very important with Non-doers being much more 
likely to say that diarrhea is "not serious." Using testimonials of people who have had diarrhea and caregivers who have lost children to diarrhea may be effective in changing this erroneous perception.

Perceived divine will is a determinant that is usually studied with BA but has not been systematically studied in many other studies of determinants of HW, despite the fact that the HBM has been used for many years to suggest various influences on health care, including religion (40). This determinant was also found to be an important driver of HW behavior in Bangladesh. In this study, Non-doers were much more likely to believe that it was God's will when one gets diarrhea. Reminding people who adhere to Islam of key verses that promote handwashing in the Quran (e.g., Surah 5, Ayat 6) (41) may be a useful way to address this determinant.

Several positive consequences of HWWS after defecation were found to be important enablers in this study. Doers of this behavior were much more likely to say that HWWS after defecation enables them to "feel clean" and keeps them "free from illness."

\section{Limitations of the study}

This study has a number of limitations. First, given that this study was only done in a limited urban area, the results should not be generalized to the rest of the country or other countries. Second, by design (as a means to make the analysis easier for practitioners and the method replicable by more practitioners), the BA approach does not consider respondents' socio-economic information including level of education, level of income, living conditions, etc., which may lead to some confounding or interaction of variables. Finally, as another means to make the tool easy to use (and tabulation of results easy to do), the questions on some determinants that are assessed are closed-ended and may lead to some bias that may be avoidable through use of more open-ended questions. However, this changes to the BA methodology, could make it harder to use by practitioners with less personnel, time, statistical skill, and funding for formative research. 


\section{Way forward}

This study identified important beliefs and responses associated with eight different determinants of HWWS after defecation in this Bangladesh urban population. An effective behavior change strategy for HWWS after defecation is required to address multiple beliefs and behavioral determinants, reducing barriers and leveraging enablers identified in this study. As an important part of the Barrier Analysis process, project staff and other partners will now develop both cost-effective and sustainable messages and activities that address the important beliefs and barriers to behavioral adoption and that leverage the enablers found in this study. For example, an intervention to improve access to low-cost soap would be educating the population (and doing demonstrations) on how to use soapy water (detergent powder mixed with water) as a means to substantially reduce the cost of hand washing, as has been done in other projects in Bangladesh. To increase cues for action, reminder stickers can be put in key places in the home (e.g. in sight when using the latrine or toilet) and designated hand washing stations can be encouraged. To increase perceived positive social norms, people - especially those found to be important influencers of this behavior (e.g., teachers, doctors) - can be videoed modeling and giving testimonials in each neighborhood on why and how they do the behavior and distributed over social media and other means. Activities can be used to make this sometimes-invisible behavior visible (e.g., stickers to put on households that say, "We wash our hands with soap!" or lapel pins with the same message). To increase the perception that diseases linked with not HWWS are serious (to address perceived severity), country-wide data on deaths from diarrhea and other WASH-related diseases can be disseminated, and testimonials by people who have lost or almost lost family members due to WASH-related diseases can be used. To address perceived divine will, religious leaders can be assisted in creating sermon outlines using verses from the Quran that promote HWWS, and assisted in creating radio spots on this. Essay contests can be used to encourage people to name positive consequences of the behavior (as a means to increase perceived positive consequences of HWWS). To increase perceived action efficacy, information on the 
effectiveness of HWWS in decreasing diarrhea, pneumonia, cholera, COVID-19, and other diseases can be disseminated using social and traditional media, and project staff.

\section{Conclusion}

A host of important behavioral determinants were found to be associated with HWWS after defecation

in this population. A broad set of activities and messages - based on key beliefs and responses

associated with these determinants - will most likely be needed to significantly scale HWWS in this and

other populations. Barrier Analysis is an important and easy-to-use tool for rapidly identifying beliefs

and behavioral determinants of key WASH and other sector behaviors.

\section{References}

1. Curtis V, Cairncross S. Effect of washing hands with soap on diarrhoea risk in the community: A systematic review [Internet]. Vol. 3, Lancet Infectious Diseases. Lancet Publishing Group; 2003 [cited 2020 Jul 7]. p. 275-81. Available from: https://pubmed.ncbi.nlm.nih.gov/12726975/

2. Luby SP, Agboatwalla M, Feikin DR, Painter J, Billhimer W, Altaf A, et al. Effect of handwashing on child health: A randomised controlled trial. Lancet [Internet]. 2005 Jul 16 [cited $2020 \mathrm{Jul}$ 7];366(9481):225-33. Available from: http://www.thelancet.com/article/S0140673605669127/fulltext

3. Strunz EC, Addiss DG, Stocks ME, Ogden S, Utzinger J, Freeman MC. Water, Sanitation, Hygiene, and Soil-Transmitted Helminth Infection: A Systematic Review and Meta-Analysis. PLoS Med [Internet]. 2014 [cited 2020 Jul 7];11(3). Available from: /pmc/articles/PMC3965411/?report=abstract

4. Alzyood M, Jackson D, Aveyard H, Brooke J. COVID-19 reinforces the importance of handwashing. J Clin Nurs [Internet]. 2020 [cited 2021 Jan 3]; Available from: https://orcid.org/0000-0001-51333356

5. Centers for Disease Control and Prevention. Hand Hygiene Recommendations | CDC [Internet]. 2020 [cited 2021 Jan 3]. Available from: https://www.cdc.gov/coronavirus/2019-ncov/hcp/handhygiene.html?CDC_AA_refVal=https\%3A\%2F\%2Fwww.cdc.gov\%2Fcoronavirus\%2F2019ncov\%2Fhcp\%2Fhand-hygiene-faq.html

6. Bartram J, Cairncross S. Hygiene, Sanitation, and Water: Forgotten Foundations of Health. PLoS Med [Internet]. 2010 Nov 9 [cited 2020 Jul 7];7(11):e1000367. Available from: https://dx.plos.org/10.1371/journal.pmed.1000367

7. Hirai M, Graham JP, Mattson KD, Kelsey A, Mukherji S, Cronin AA. Exploring Determinants of Handwashing with Soap in Indonesia: A Quantitative Analysis. Int J Environ Res Public Health. 2016;13(9).

8. Parveen S, Nasreen S, Allen J V., Kamm KB, Khan S, Akter S, et al. Barriers to and motivators of 
handwashing behavior among mothers of neonates in rural Bangladesh. BMC Public Health. 2018;18(1):1-13.

9. Dreibelbis R, Winch PJ, Leontsini E, Hulland KRS, Ram PK, Unicomb L, et al. The Integrated Behavioural Model for Water, Sanitation, and Hygiene: A systematic review of behavioural models and a framework for designing and evaluating behaviour change interventions in infrastructure-restricted settings [Internet]. Vol. 13, BMC Public Health. BMC Public Health; 2013 [cited 2020 Jul 7]. Available from: https://pubmed.ncbi.nlm.nih.gov/24160869/

10. Zangana A, Shabila N, Heath T, White Id S. The determinants of handwashing behaviour among internally displaced women in two camps in the Kurdistan Region of Iraq. 2020 [cited 2020 Jul 7]; Available from: https://doi.org/10.1371/journal.pone.0231694

11. International Centre for Diarrheal Diseases Research, Bangladesh (icddr B, WaterAid Bangladesh, Ministry of Local Government RD and C. Bangladesh National Hygiene Survey: Preliminary Report. 1389;

12. Curtis VA, Danquah LO, Aunger R V. Planned, motivated and habitual hygiene behaviour: an eleven country review. [cited 2020 Jul 7]; Available from: http://www.globalhandwashing.org/

13. Hulland KRS, Leontsini E, Dreibelbis R, Unicomb L, Afroz A, Dutta NC, et al. Designing a handwashing station for infrastructure-restricted communities in Bangladesh using the integrated behavioural model for water, sanitation and hygiene interventions (IBM-WASH). BMC Public Health. 2013;13(1).

14. Halder AK, Tronchet C, Akhter S, Bhuiya A, Johnston R, Luby SP. Observed hand cleanliness and other measures of handwashing behavior in rural Bangladesh. BMC Public Health [Internet]. 2010 Dec 9 [cited 2020 Aug 16];10(1):545. Available from:

https://bmcpublichealth.biomedcentral.com/articles/10.1186/1471-2458-10-545

15. Luby SP, Halder AK, Tronchet C, Akhter S, Bhuiya A, Johnston RB. Household characteristics associated with handwashing with soap in rural Bangladesh. Am J Trop Med Hyg [Internet]. 2009 Nov [cited 2020 Aug 16];81(5):882-7. Available from:

https://pubmed.ncbi.nlm.nih.gov/19861626/

16. Davis T and Srinivasan A. Ebola Barrier Analysis Compendium: Summary of Barrier Analysis Studies on Ebola-related Behaviors. [Internet]. 2016 [cited 2020 Dec 27]. Available from: https://www.fsnnetwork.org/sites/default/files/BA_Ebola_Compendium.pdf

17. GARBA MB. Comparative Study of Behavioural Determinants of Adopters and Non-Adopters of Birth Preparedness and Complications Readiness Among Pregnant Women in Zaria Metropolis, Kaduna State. Medical College of Nigeria.; 2017.

18. Lian TZA, Weatherson J. Barriers and enablers of Agriculture and Nutrition behaviours in Chin State, Myanmar: Formative Research for Productive Agriculture through Community Engagement ( PACE ). 2017;1-60. Available from: https://www.lift-fund.org/sites/liftfund.org/files/publication/LIFT_CRS_PACE Barrier Analysis Report 2017.pdf

19. Rizaldo Q, Karim M. Nutrition approaches in the Fish for Livelihoods project:Nutrition Approaches in The Fish for Livelihoods Project. [Internet]. Penang, Malaysia; 2020. Available from: https://digitalarchive.worldfishcenter.org/bitstream/handle/20.500.12348/4213/267db5d0113c af76676feccef397a381. pdf?sequence $=2$ \&isAllowed=y 
20. Rizaldo Q. Nutrition approaches in the Fish for Livelihoods project | FISH CRP [Internet]. Program Brief. 2020 [cited 2020 Dec 27]. Available from: https://fish.cgiar.org/publications/nutritionapproaches-fish-livelihoods-project

21. Acharya A, Rana PP, Pun BK, Thapa B. Consumption of iron-rich foods among adolescent girls in Nepal: identifying behavioural determinants. F Exch - Emerg Nutr Netw ENN [Internet]. 2018;(57):17-9. Available from: https://www.ennonline.net/fex/57/ironadolescentgirlsnepal

22. Perera SM. Barrier analysis of infant and young child feeding and maternal nutrition behaviours among IDPs in northern and southern Syria Field Exchange 59, -. F Exch 59 [Internet]. 2019 [cited 2020 Dec 27];18. Available from: www.ennonline.net/fex/59/rrtbarrieranalysis

23. Brandes K. Determinants of adoption and use of a household water treatment technology: The case of the biosand filter in a rural setting of India [Internet]. TH Köln - Cologne University of Applied Science; 2017 [cited 2020 Dec 27]. Available from: https://www.researchgate.net/publication/314179801_Determinants_of_adoption_and_use_of _a_household_water_treatment_technology_The_case_of_the_biosand_filter_in_a_rural_settin g_of_India?channel=doi\&linkld=58b8ab9ea6fdcc2d14d9a442\&showFulltext=true

24. Concern Worldwide. Barrier Analysis Liberia. 2020.

25. Moyo G, Magaisa T, Pagiwa A, Kandawasvika R, Nyanga L, Gomora Z, et al. Identifying Barriers and Enablers to Exclusive Breastfeeding in Mwenezi and Chiredzi Districts, Zimbabwe. Curr Dev Nutr [Internet]. 2020 Jun 1 [cited 2020 Dec 27];4(Supplement_2):249-249. Available from: https://academic.oup.com/cdn/article/4/Supplement_2/249/5844868

26. Choudhary M, Solomon R, Awale J, Dey R. Demand-side determinants of timely vaccination of oral polio vaccine in social mobilization network areas of CORE Group polio project in Uttar Pradesh, India. BMC Infect Dis [Internet]. 2018 May 16 [cited 2020 Dec 27];18(1):222. Available from: https://bmcinfectdis.biomedcentral.com/articles/10.1186/s12879-018-3129-2

27. Seiler-Martinez Peace Corps Guatemala Santa Lucia Milpas Altas A, Theresa Pesl Murphrey Gary Wingenbach Leonardo Lombardini G. Tools of the Profession Barrier Analysis as a Tool to Inform Extension Activity Planning: Insights from Guatemala. J Int Agric Ext Educ [Internet]. [cited 2020 Dec 27];25:7. Available from: https://www.fsnnetwork.org/resour

28. Ghimire S, Shrestha N, Callahan K. Barriers to Dietary Salt Reduction among Hypertensive Patients - PubMed. J Nepal Heal Res Counc [Internet]. 2018 [cited 2020 Dec 27];16(39)(AprJun):124-30. Available from: https://pubmed.ncbi.nlm.nih.gov/29983423/

29. Kouyaté RA, Ahmed S, Haver J, McKaig C, Akter N, Nash-Mercado A, et al. Transition from the Lactational Amenorrhea Method to other modern family planning methods in rural Bangladesh: Barrier analysis and implications for behavior change communication program intervention design. Eval Program Plann [Internet]. 2015 Jun 1 [cited 2018 Oct 1];50:10-7. Available from: https://www.sciencedirect.com/science/article/pii/S014971891400130X

30. Kouyaté RA, Ahmed S, Haver J, McKaig C, Akter N, Nash-Mercado A, et al. Transition from the Lactational Amenorrhea Method to other modern family planning methods in rural Bangladesh: Barrier analysis and implications for behavior change communication program intervention design. Eval Program Plann. 2015;50:10-7.

31. The TOPS Program. Designing for Behavior Change: For Agriculture, Natural Resource 
Management, and Gender. 2016;(November). Available from: www.thetopsprogram.org

32. Kittle BL. A Practical Guide to Conducting a Barrier Analysis. 2017;1-186. Available from: http://www.coregroup.org/storage/barrier/Practical_Guide_to_Conducting_a_Barrier_Analysis_ Oct_2013.pdf

33. Ram PK, Nasreen S, Kamm K, Allen J, Kumar S, Rahman MA, et al. Impact of an Intensive Perinatal Handwashing Promotion Intervention on Maternal Handwashing Behavior in the Neonatal Period: Findings from a Randomized Controlled Trial in Rural Bangladesh. Biomed Res Int. 2017;2017.

34. Hoque BA. Handwashing practices and challenges in Bangladesh. In: International Journal of Environmental Health Research [Internet]. Int J Environ Health Res; 2003 [cited 2020 Aug 16]. Available from: https://pubmed.ncbi.nlm.nih.gov/12775383/

35. Jumaa PA. Hand hygiene: Simple and complex. Int J Infect Dis. 2005;9(1):3-14.

36. White $\mathrm{S}$, Thorseth AH, Dreibelbis R, Curtis V. The determinants of handwashing behaviour in domestic settings: An integrative systematic review. Int J Hyg Environ Health [Internet]. 2020 [cited 2020 Aug 16];227:113512. Available from: www.elsevier.com/locate/ijheh

37. Rahman MJ, Nizame FA, Unicomb L, Luby SP, Winch PJ. Behavioral antecedents for handwashing in a low-income urban setting in Bangladesh: An exploratory study. BMC Public Health. 2017;17(1):1-10.

38. Zeigheimat F, Ebadi A, Rahmati-Najarkolaei F, Ghadamgahi F. An investigation into the effect of health belief model-based education on healthcare behaviors of nursing staff in controlling nosocomial infections. J Educ Health Promot [Internet]. 2016 [cited 2020 Dec 27];5(1):23. Available from: /pmc/articles/PMC4960766/?report=abstract

39. Jones CL, Jensen JD, Scherr CL, Brown NR, Christy K, Weaver J. The Health Belief Model as an Explanatory Framework in Communication Research: Exploring Parallel, Serial, and Moderated Mediation HHS Public Access. Heal Commun. 2015;30(6):566-76.

40. Kirn JM. Religion and the health belief model. J Relig Heal [Internet]. 1991 Dec [cited 2020 Dec 27];30(4):321-9. Available from: https://link.springer.com/article/10.1007/BF00986903

41. The Conversation. What Islamic hygienic practices can teach when coronavirus is spreading [Internet]. [cited 2020 Dec 27]. Available from: https://theconversation.com/what-islamichygienic-practices-can-teach-when-coronavirus-is-spreading-133221 